\title{
Seasonal pelage variation in the masked shrew Sorex cinereus: a demographic perspective
}

\author{
Sherry C. RINEHART-WHITT** and John F. PAGELS**
}

\begin{abstract}
Rinehart-Whitt S. C. and Pagels J. F. 2000. Seasonal pelage variation in the masked shrew Sorex cinereus: a demographic perspective. Acta Theriologica 45: 111-116.

Pelage characteristics of the masked shrew Sorex cinereus Kerr, 1792, were studied with emphasis on season, age and gender to determine the relationship of fur to life history characteristics. A total of 140 shrews was collected from 1985-1989 at five montane sites in Virginia. Hair length $(\mathrm{mm}$ ) and hair density (no. of hairs/mg fat-free skin) were measured to identify the extent of pelage variation. Shrews caught in winter had significantly longer $(4.4 \mathrm{~mm})$ and more dense $(8100$ hairs $/ \mathrm{mg})$ hair than shrews caught in summer ( $3.6 \mathrm{~mm}$ and 7767 hairs $/ \mathrm{mg}$, respectively). Age class had a significant effect on hair density in summer; immature shrews (age class I) had the greatest median hair densities (7985 hairs/mg) of any age class. Old adults (age class IV) had the lowest hair density during both summer and winter, possibly reflecting an old-age molt. Females had significantly higher hair densities (8301 hairs/mg) than males (7509 hairs/mg) during summer. Due to the lower energy costs of morphological adjustments compared to physiological changes, alteration of pelage in $S$. cinereus may be an important mechanism to decrease total energy demands as has been described in many other small mammals.

Department of Biology, Box 842012, Virginia Commonwealth University, Richmond, Virginia, USA 23284-2012
\end{abstract}

Key words: Sorex cinereus, pelage variation, seasonal variation

\section{Introduction}

Shrews may be stressed in cold environments due to rapid heat loss, high metabolic rates and high caloric requirements; however, as Merritt and Adamerovich (1991) and Merritt (1995) summarized, they demonstrate numerous mechanisms that enhance overwinter survivorship. These mechanisms include behavioral adjustments such as food hoarding, foraging in a microclimate characterized by a stable thermal regime, and decreased activity, in addition to anatomical and physiological adjustments that include decreased body mass (Pucek 1970) and increased thermogenic capacity in winter (Merritt 1995).

Sorex cinereus Kerr, 1792 because of its tiny size is suitable for study of mechanisms in soricines that facilitate use of cold environments and general

\footnotetext{
* Present address: Department of Pharmacology, University of South Alabama, Mobile, Alabama, USA 36688

** To whom reprint requests should be sent: Virginia Commonwealth University, Department of Biological Sciences, 816 Park Avenue, PO Box 842012, Richmond, Virginia, USA 23284-2012, fax: (804) 828-0503, e-mail: jpagels@saturn.vcu.edu
} 
survivorship. Sorex cinereus occurs throughout much of northern North America in a variety of moist, cool habitats characterized by abundant ground cover (Merritt 1995, Pagels et al. 1994). Winter temperatures of the microhabitat, ie subsurface, are higher and relatively stable compared to surface temperatures, but far below requirements for thermoneutrality in S. cinereus (Merritt 1995). Merritt (1995) observed that overwinter survivorship was enhanced in part due to elevated metabolism and increased nonshivering thermogenesis in autumn and winter. Merritt (1995) also found that body mass for S. cinereus was lower in winter than in summer and that conductance, measured as oxygen consumption, was predictably higher in smaller February animals than in larger animals measured in April. Merritt (1995) did not evaluate seasonal changes in pelage insulation of S. cinereus. Based on studies of other similar-sized soricines (Borowski 1958, Ivanter 1994), he suggested that changes in pelage may help reduce conductance in winter. While alteration in the insulative capacity of the pelage can be an effective mechanism for accommodating seasonal temperature changes (Ivanter 1994), pelage in small mammals insulation can only develop to a certain thickness before locomotion is compromised (Hart 1971).

Most efforts to document changes in pelage insulation as a mechanism for thermoregulation have focused on rodents (Huestis 1931, Hart and Heroux 1953, Hart 1971, Sealander 1972, Cherry and Verner 1975). Studies of shrew pelage have included descriptions of molting patterns (Findley and Jones 1956, Borowski 1963 and 1964), seasonal adjustments in pelage (Borowski 1958, 1973, Skarén 1973, Dew et al. 1998), the role of hair in summer versus winter thermal conductance (Bozinovic and Merritt 1992), and the microstructure of hair (Ivanter 1994).

We examined pelage of $S$. cinereus with respect to season and demographic characteristics. Our primary question was: Are hair density and hair length greater during winter than in summer? Ancillary questions included: (1) Are changes in pelage correlated with age? and (2) Is there a relationship between pelage adjustments and gender?

\section{Material and methods}

One hundred and forty $S$. cinereus were pitfall trapped in the period 1985 to 1989 . The sites, all in Virginia, were: Cabin Creek (CC), elevation 1341 m, Grayson County, N 36³7', W 81³1'; AUG,

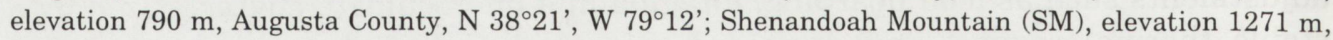
Rockingham County, N 38 $20^{\prime}$, W $79^{\circ} 12^{\prime}$; and two areas in Highland County each comprised of three sites in close proximity, Hi-12/13/14, mean elevation $1158 \mathrm{~m}$, at approximately $\mathrm{N} 38^{\circ} 34^{\prime}$, W $79^{\circ} 39^{\prime}$; and Hi-16/18/21, mean elevation $1229 \mathrm{~m}$, at approximately N $38^{\circ} 27^{\prime}$, W $79^{\circ} 41^{\prime}$. Periodic deep snow and frozen soils present in January and February at these elevations precluded sampling in those months; however, shrews should have developed winter pelage before that time. Temperatures at our sites, which averaged $-6.7^{\circ} \mathrm{C}$ in December and January over the 5-year study period are comparable to mean monthly temperatures for Powdermill Nature Reserve in Pennsylvania, which averaged $-7.8^{\circ} \mathrm{C}$ in December and January over a 25 -five year period (J. F. Merritt, unpub. data).

Traps were checked biweekly and specimens were fixed in $10 \%$ formalin solution, fluid preserved in alcohol and deposited in the Virginia Commonwealth University Mammal Collection. Three skin patches that ranged in area from $1-3 \mathrm{~mm}^{2}$ were cut from the middorsum of each shrew. The hairs 
from each of the three patches were then removed by pulling them from the follicle and placed in individual petri dishes. The dishes were placed on a counting grid and raw counts were randomly taken from 10 squares.

Although Borowski (1958) concluded that all preserved shrews demonstrated equivalent shrinkage, we standardized potential differences in skin patch size and body weight by measures of skin mass. Fat was removed from the skin patches with a chloroform/methanol solution in a soxhlet apparatus. Skin was oven-dried (Sealander 1972) and weighed on a microbalance to $0.001 \mathrm{mg}$. Mass of the three patches was averaged, and hair density was expressed as the number of hairs per milligram of fat-free skin.

Hairs were randomly selected from each skin patch and their lengths measured to the nearest 0.1 $\mathrm{mm}$ by ocular micrometer at 100x. Mean guard hair length and mean underhair length were determined for 60 guard hairs and 60 underhairs. Ivanter (1994) identified two types of guard hairs in several soricine species. Type I guard hair is longer and wider than Type II. We noted guard hairs, presumably Type II that resembled an intermediary between woolly hairs and guard hairs (Ivanter 1994). Only hairs that could be definitively identified as underhair or guard hair were included in our counts.

Relative ages of shrews were determined based on tooth wear in cleaned skulls; we did not attempt to determine if an animal had overwintered. Shrews were age-classed following Rudd (1955): I Immature young, II - Young, III - Young Adult, and IV - Old Adult. Shrews were dissected to determine gender.

Based on dates given in the literature as typical spring and fall molts for several mammals (Huestis 1931, Findley and Jones 1956, Rust 1962, Skarén 1973), shrews were categorized as either winter or summer. Shrews captured from 1 November to 30 April were winter animals, those captured between 1 May to 31 October were summer animals.

Seasonal and gender differences were examined using $t$-tests (Zar 1984). Due to small sample size non-parametric Kruskal-Wallis tests (Zar 1984) were used to examine age-class differences. Significant differences among age classes were isolated by Dunn's method of multiple comparison (Zar 1984). The relationship between guard hair length and underhair length was examined with linear regression. Variance of the hair density ratio (no. of hairs/mg fat-free skin), was deemed acceptable by examination of residual versus predicted values for the natural logarithm of density (Zar 1984). Preliminary analyses of hair densities and hair lengths based on geographic location of capture indicated no differences among the sites (all $p>0.25$ ); location was subsequently eliminated from the analyses. Results were deemed statistically significant if $p<0.05$.

\section{Results}

Winter hair density was significantly greater than summer hair density $(p<$ 0.05). Similarly, winter guard hair length and underhair length were significantly greater $(p<0.05)$ when compared to length of summer guard hair and underhair (Table 1). The relationship between guard hair length and underhair length was positive for both the winter $\left(r^{2}=0.991, p<0.01\right)$ and summer groups $\left(r^{2}=0.971\right.$, $p<0.01$ ); guard hair length alone was used as a dependent variable to represent both hair types in the analyses.

In winter, hair densities did not differ between males and females $(p=0.14)$, although hair length was greater in males than females $(p=0.03)$. In summer, females had a greater mean hair density than males; however, the difference was marginally significant ( $p=0.05$; Table 1$)$. Summer hair lengths were not significantly different ( $p=0.24$; Table 1 ) between genders.

Age class had no effect $(p=0.24)$ on hair densities in winter, while winter hair lengths differed among age classes $(p<0.01)$. Age class III had the greatest median hair length in winter, followed by age class II, age class IV, and age class I. Age class I was significantly different from age classes II and III by pairwise comparison. 
Table 1. Effect of gender on guard hair length and hair density in Sorex cinereus during the winter and summer seasons at five montane sites in western Virginia.

\begin{tabular}{|c|c|c|c|c|c|}
\hline \multirow[t]{2}{*}{ Gender } & \multirow[t]{2}{*}{$n$} & \multicolumn{2}{|c|}{$\begin{array}{l}\text { Guard hair length } \\
(\mathrm{mm})\end{array}$} & \multicolumn{2}{|c|}{$\begin{array}{c}\text { Hair density } \\
\text { (no. hairs/mg fat-free skin) }\end{array}$} \\
\hline & & Mean & $\mathrm{SD}$ & Mean & SD \\
\hline \multicolumn{6}{|c|}{ Summer } \\
\hline Male & 44 & 3.6 & 0.65 & 7509 & 1795 \\
\hline Female & 49 & 3.6 & 0.25 & 8301 & 2000 \\
\hline \multicolumn{6}{|c|}{ Winter } \\
\hline Male & 25 & 4.7 & 0.75 & 8734 & 1851 \\
\hline Female & 22 & 4.7 & 0.75 & 7650 & 2601 \\
\hline
\end{tabular}

A trend was evident in median summer hair densities as follows: age class I > II > III $>$ IV. Although age class IV individuals were excluded from analysis due to small sample size, summer hair densities differed significantly $(p=0.01)$ among the remaining age classes. Multiple comparison isolated significant differences for age classes I and III only $(p=0.05)$. No significant difference $(p=0.47)$ was found among age classes for summer hair lengths.

\section{Discussion}

Insulation allows mammals to decrease conductive heat loss in cold environments, which also reduces costs of thermogenesis and metabolism. For example, despite high metabolism, on very cold days a shrew could not maintain a high body temperature without adequate insulation (Spotila and Gates 1975). Merritt (1995) reported that elevated metabolism and increased nonshivering thermogenesis in $S$. cinereus during autumn and winter facilitated homeothermy. However, a maladaptive increase in thermal conductance, as calculated based on body mass, was also noted in younger, smaller animals captured in autumn (Merritt 1995). Adjustments that reduce thermal conductance should benefit a small endotherm living outside its zone of thermoneutrality. Using a technique that involved hair removal of summer and winter shrews, Bozinovic and Merritt (1992) found that seasonal changes in the pelage of Blarina brevicauda accounted for decreased thermal conductance during winter compared to summer.

Greater hair densities and lengths in $S$. cinereus in winter relative to summer were similar to pelage changes observed in several other species of small mammals (Borowski 1958, 1964 and 1973, Cherry and Verner 1975, Hart and Heroux 1953, Sealander 1972). Dew et al. (1998) found no seasonal differences in hair density of Blarina carolinensis from eastern Virginia, but found Type I guard hair was 1.3 times longer in winter than in summer. Chappell (1980), using a different measuring technique and a sample size of two, found a slightly shorter hair length for $S$. cinereus from Alaska than we report. We believe it is unlikely that the measurements parallel ours. 
As noted, pelage did not differ significantly among specimens from our five southern Appalachian localities. At Monterey, Virginia (approximately the mean elevation of our sites) snowfall averaged $32.5 \mathrm{~cm}$ in January over the 5-year collection period (National Oceanic and Atmospheric Administration Weather Data Archives, 1985-1989). Arguably, the pelage changes we observed were as critical as adjustments for $S$. cinereus found at higher latitudes where subterranean thermal regimes might be more stable as a result of greater snow cover in winter months. Merritt (1995) found at his Pennsylvania site that subsurface temperatures in February of one year were $20^{\circ} \mathrm{C}$ higher than surface temperatures.

Timing of molts and the reproductive cycle must be integrated with respect to each other and seasonal cycles in order to provide a species with the highest adaptability (Ling 1970). Sorex araneus has evolved an effective strategy for integrating these two cycles; the spring molt in $S$. araneus does not take place until the completion of sexual maturation (Skarén 1973). We found that male and female $S$. cinereus differed from each other in hair density and hair length measures in both summer and winter, possibly reflecting differences in energy requirements during the reproductive season.

Significant differences in winter hair lengths were found among all age classes. Class III individuals of $S$. cinereus had significantly lower summer hair densities than class I individuals; class I individuals had the highest pelage density of any age class. Presumably, young would benefit from a thick coat due to their smaller size. Winter size reduction is well-documented in shrews (Pucek 1970), and Borowski (1958) reported that seasonal differences in hair density resulted from stretching of the skin associated with seasonal size changes. However, because our analysis examined density relative to weight of skin rather than area, we suggest that differences observed in pelage characteristics between immature adults and adults were indicative of distinct thermoregulatory requirements rather than seasonal variation in size. The trend of lower summer hair densities in age IV individuals may have represented the onset of an old-age molt (Borowski 1963).

Our data support Merritt's (1995) hypothesis that changes in pelage of $S$. cinereus may help reduce conductance in winter. By investing energy in denser, longer pelage during less stressful periods, $S$. cinereus reduces thermogenic and metabolic costs during colder periods. Additionally, pelage changes may compensate for individual requirements faced by shrews of different age classes and genders.

Acknowledgements: We thank D. Young, P. Williamson, and C. Blem for valuable insight on this project, A. Mills for technical assistance, and G. Kirkland, J. Merritt, J. Orrock, and two anonymous reviewers for comments on an earlier draft of the manuscript. Support was provided in part by funds to Pagels from the Virginia Department of Game and Inland Fisheries Nongame Program and matching grants from the George Washington and Jefferson National Forests, U.S. Forest Service.

\section{References}

Borowski S. 1958. Variations in density of coat during the life cycle of Sorex araneus araneus. Acta Theriologica 2: 286-289. 
Borowski S. 1963. Old-age moult in the common shrew Sorex araneus Linnaeus, 1758. Acta Theriologica 7: 374-375.

Borowski S. 1964. Moult of shrews (Sorex L.) under laboratory conditions. Acta Theriologica 8: 125-135.

Borowski S. 1973. Variations in coat and colour in representatives of the genera Sorex L. and Neomys Kaup. Acta Theriologica 18: 247-279.

Bozinovic F. and Merritt J. F. 1992. Summer and winter thermal conductance of Blarina brevicauda (Mammalia: Insectivora: Soricidae) inhabiting the Appalachian Mountains. Annals of the Carnegie Museum 61: 33-37.

Chappell M. A. 1980. Insulation, radiation, and convection in small Arctic mammals. Journal of Mammalogy 61: 268-277.

Cherry R. H. and Verner L. 1975. Seasonal acclimatization to temperature in the prairie vole, Microtus ochrogaster. American Midland Naturalist 94: 354-360.

Dew E. M., Carson K. A. and Rose R. K. 1998. Seasonal changes in brown fat and pelage in southern short-tailed shrews. Journal of Mammalogy 79: 271-278.

Findley J. S. and Jones J. K. Jr 1956. Molt of the short-tailed shrew, Blarina brevicauda. American Midland Naturalist 56: 246-249.

Hart J. S. and Heroux O. 1953. A comparison of some seasonal and temperature-induced changes in Peromyscus: cold resistance, metabolism and pelage insulation. Canadian Journal of Zoology 31: 528-534.

Hart J. S. 1971. Rodents. [In: Comparative physiology of thermoregulation, Mammals. G. C. Whittow, ed]. Academic Press, New York: 1-149.

Huestis R. R. 1931. Seasonal pelage differences in Peromyscus. Journal of Mammalogy 12: 372-375.

Ivanter E. V. 1994. The structure and adaptive peculiarities of pelage in soricine shrews. [In: Advances in the biology of shrews. J. F. Merritt, G. L. Kirkland Jr and R. K. Rose, eds]. Special Publication, Carnegie Museum of Natural History 18: 441-454.

Ling J. K. 1970. Pelage and molting in wild mammals with special reference to aquatic forms. The Quarterly Review of Biology 45: 16-54.

Merritt J. F. 1995. Seasonal thermogenesis and changes in body mass of masked shrews, Sorex cinereus. Journal of Mammalogy 76: 1020-1035.

Merritt J. F. and Adamerovich A. 1991. Winter thermoregulatory mechanisms of Blarina brevicauda as revealed by radiotelemetry. [In: The biology of the Soricidae. J. S. Findley and T. L. Yates, eds]. Special Publication, The Museum of Southwestern Biology 1: 47-64.

Pagels J. F., Uthus K. L. and Duvall H. E. 1994. The masked shrew, Sorex cinereus, in a relictual habitat of the southern Appalachian Mountains. [In: Advances in the biology of shrews. J. F. Merritt, G. L. Kirkland Jr and R. K. Rose, eds]. Special Publication, Carnegie Museum of Natural History 18: 103-109.

Pucek Z. 1970. Seasonal and age change in shrews as an adaptive process. Symposia of the Zoological Society of London 26: 189-207.

Rudd R. L. 1955. Age, sex and weight comparisons in three species of shrews. Journal of Mammalogy 36: 323-338.

Rust C. C. 1962. Temperature as a modifying factor in the spring pelage change of short-tailed weasels. Journal of Mammalogy 43: 323-328.

Sealander J. 1972. Circum-annual changes in age, pelage characteristics and adipose tissue in the northern red-backed vole in interior Alaska. Acta Theriologica 17: 1-24.

Skarén U. 1973. Spring moult and onset of the breeding season of the common shrew (Sorex araneus L.) in central Finland. Acta Theriologica 18: 443-458.

Spotila J. R. and Gates D. M. 1975. Body size, insulation and optimum body temperatures of homeotherms. [In: Perspectives of biophysical ecology. D. M. Gates and R. B. Schmerl, eds]. Springer-Verlag, New York: 291-301.

Zar J. H. 1984. Biostatistical Analysis. Prentice Hall, Englewood Cliffs, New Jersey: 1-718.

Received 16 November 1998, accepted 21 June 1999. 